\title{
National Ignition Facility Frequency Converter Development
}

\author{
C. E. Barker, J. M. Auerbach, C. H. Adams, \\ S. E. Bumpas, R. L. Hibbard, C. L. Lee, \\ D. H. Roberts, J. H. Campbell, P. J. Wegner, \\ B. M. Van Wonterghem, and J. A. Caird
}

This paper was prepared for submittal to the 2nd Annual International Conference on Solid-State Lasers for Application to Inertial Confinement Fusion Paris, France October 22-25, 1996

December 9, 1996

This is a preprint of a paper intended for publication in a journal or proceedings. Since changes may be made before publication, this preprint is made available with the understanding that it will not be cited or reproduced without the permission of the author. 


\section{DISCLAIMER}

This document was prepared as an account of work sponsored by an agency of the United States Government. Neither the United States Government nor the University of California nor any of their employees, makes any warranty, express or implied, or assumes any legal liability or responsibility for the accuracy, completeness, or usefulness of any information, apparatus, product, or process

disclosed, or represents that its use would not infringe privately owned rights. Reference herein to any specific commercial product, process, or service by trade name, trademark, manufacturer, or otherwise, does not necessarily constitute or imply its endorsement, recommendation, or favoring by the United States Government or the University of California. The views and opinions of authors expressed herein do not necessarily state or reflect those of the United States Government or the University of California, and shall not be used for advertising or product endorsement purposes. 


\title{
National Ignition Facility frequency converter development
}

\author{
C. E. Barker, J. M. Auerbach, C. H. Adams, S. E. Bumpas, R. L. Hibbard, C. L. Lee, D. H. Roberts,
}

J. H. Campbell, P. J. Wegner, B. M. Van Wonterghem, and J. A. Caird

\author{
University of California \\ Lawrence Livermore National Laboratory \\ P. O. Box 5508, L-487 \\ Livermore, CA 94551-9900, USA \\ (510) 423-3282 / FAX (510) 423-9242
}

\begin{abstract}
A preliminary error budget for the third harmonic converter for the National Ignition Facility (NIF) laser driver has been developed using a root-sum-square-accumulation of error sources. Such a budget sets an upper bound on the allowable magnitude of the various effects that reduce conversion efficiency. Development efforts on crystal mounting technology and crystal quality studies are discussed.
\end{abstract}

Keywords: harmonic generation, frequency conversion, nonlinear optics, KDP

\section{Introduction}

Third harmonic generation experiments on the Beamlet laser ${ }^{1}$ have demonstrated whole-beam energy third harmonic energy conversion efficiencies of up to $80.6 \%$, as indicated by the plot in Figure $1 .{ }^{2}$ Third harmonic conversion efficiencies of up to $85 \%$ at the peak irradiance of the input laser pulse are necessary to meet current NIF power and energy requirements. At an input drive irradiance of $3.3 \mathrm{GW} / \mathrm{cm}^{2}$ incident upon an $11 \mathrm{~mm}$ type I KDP second harmonic generation crystal followed by a type II KD*P mixing crystal, the ideal plane wave third harmonic conversion efficiency, including absorption in the crystals, is $90.8 \%$. This sets a total peak conversion efficiency error budget of $5.8 \%$.

Third Harmonic Generation with $32 \mathrm{~cm}$ Xtals

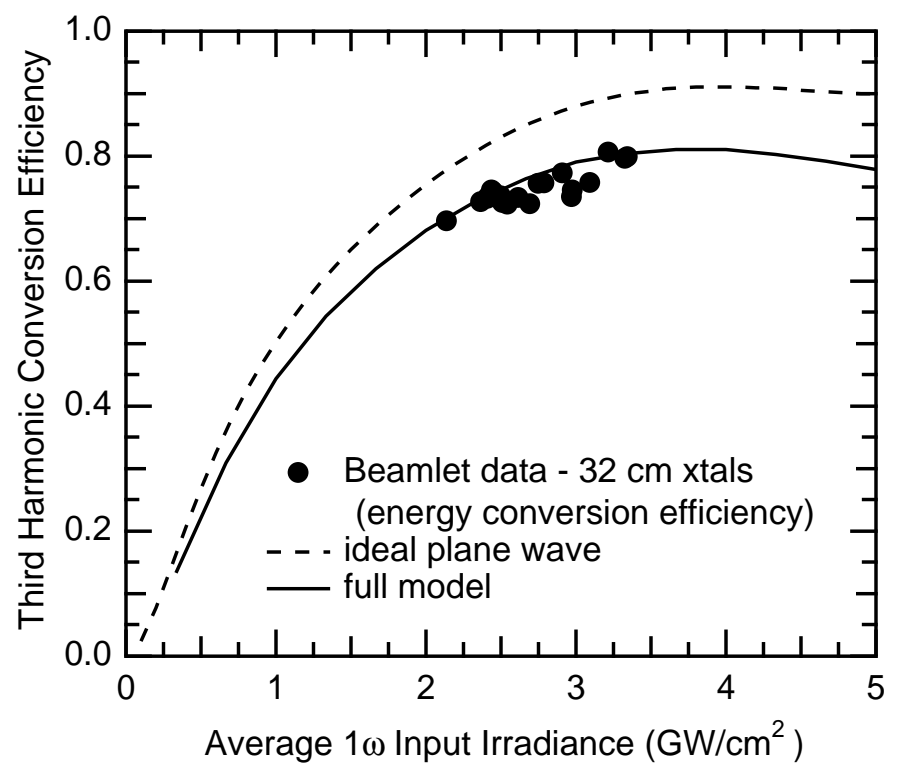

Figure 1. Third harmonic conversion efficiency versus input $1 \omega$ drive irradiance. These data were recorded with a $29.6 \mathrm{~cm}$ aperture beam incident upon $32 \mathrm{~cm}$ square KDP. crystals. 


\section{Preliminary Error Budget}

The frequency converter error budget must account for many effects. The effects that act to reduce harmonic generation efficiency can be grouped into three sets of terms: loss terms, dynamic range terms, and angular sensitivity terms. An upper bound on the allowable magnitude of the various error budget terms can be determined from a root-sum-square accumulation of errors. The allocation of the $5.8 \%$ error budget in a root-sum-square accumulation of the three groups of error terms listed above is given in Table 1 .

Table 1. Frequency converter error budget

\begin{tabular}{|c|c|}
\hline Source of efficiency reduction & Magnitude \\
\hline \hline Loss terms & $2.8 \%$ \\
\hline Dynamic range terms & $1 \%$ \\
\hline Angular sensitivity terms & $5 \%$ \\
\hline Total root-sum-square accumulation & $5.8 \%$ \\
\hline
\end{tabular}

A number of effects, including the presence of phase-modulated bandwidth and depolarization as well as surface reflectivities, can be treated as losses. These terms, which lead to a net reduction of $2.8 \%$ in conversion efficiency, are summarized in Table 2. The dynamic range terms are listed in Table 3. Since we are concerned only with peak irradiance, the spatial and temporal edges of the pulse are not included in the error budget.

Table 2. Loss terms

\begin{tabular}{|l|l|c|l|}
\hline Effect & Budget & $\begin{array}{c}\text { Efficiency } \\
\text { reduction }\end{array}$ & Comments \\
\hline \hline bandwidth & $30 \mathrm{GHz}$ & $1.4 \%$ & required for SBS suppression \\
\hline coating reflectivity & $\begin{array}{l}\text { SHG xtal } \\
\mathrm{R}=0.1 \% \text { (both faces) }\end{array}$ & $0.2 \%$ & $\begin{array}{l}\text { SHG xtal: } 1 \omega / 2 \omega \text { compromise silicone/sol-gel } \\
\text { coatings }\end{array}$ \\
\cline { 2 - 4 } & $\begin{array}{l}\text { THG xtal } \\
\mathrm{R}=0.9 \% \text { (input) } \\
\mathrm{R}=0.1 \% \text { (output) }\end{array}$ & $1.0 \%$ & $\begin{array}{l}\text { THG xtal: } 1 \omega / 2 \omega \text { compromise sol-gel coating on } \\
\text { input; } 3 \omega \text { optimized sol-gel coating on output }\end{array}$ \\
\hline $\begin{array}{l}\leq \pm 2.5^{\circ} \text { rotation } \\
\text { depolarization } \\
\text { absorption in bulk } \\
\text { crystal }\end{array}$ & $\begin{array}{l}5.8 \% / \mathrm{cm} @ 1 \omega \\
\text { (o-wave in SHG) }\end{array}$ & $\leq 0.2 \%$ & type I/II insensitive to depolarization \\
\hline
\end{tabular}

Table 3. Dynamic range terms

\begin{tabular}{|l|l|c|l|}
\hline Effect & Budget & $\begin{array}{c}\text { Efficiency } \\
\text { reduction }\end{array}$ & Comments \\
\hline \hline amplitude modulation & $1.2: 1$ uniform distribution & $1 \%$ & Irradiance distribution will be gaussian-like \\
\hline $\begin{array}{l}\text { spatial and temporal } \\
\text { edges }\end{array}$ & N/A & 0 & $\begin{array}{l}\text { Spatial and temporal edges of the pulse affect whole } \\
\text { beam energy conversion efficiency, not peak irradiance } \\
\text { efficiency }\end{array}$ \\
\hline
\end{tabular}

Because mix ratio control in the type I / type II design is accomplished by angular detuning of the doubler, this design is very sensitive to angular errors. ${ }^{3}$ From the plot given in Figure 2, we find that the angular sensitivity of third harmonic generation is dominated by detuning in the doubler crystal. An angular error of $\pm 40 \mu \mathrm{rad}$ internal to the doubling crystal results in a third harmonic conversion efficiency reduction of 5\%. Consequently, the preliminary angular error budget will be set at $\pm 40 \mu \mathrm{rad}$, and apportioned entirely to the doubler. The terms that contribute to the angular sensitivity are given in Table 4. Of particular concern are long-scale-length surface figure and phasematching angle uniformity of the crystals. 


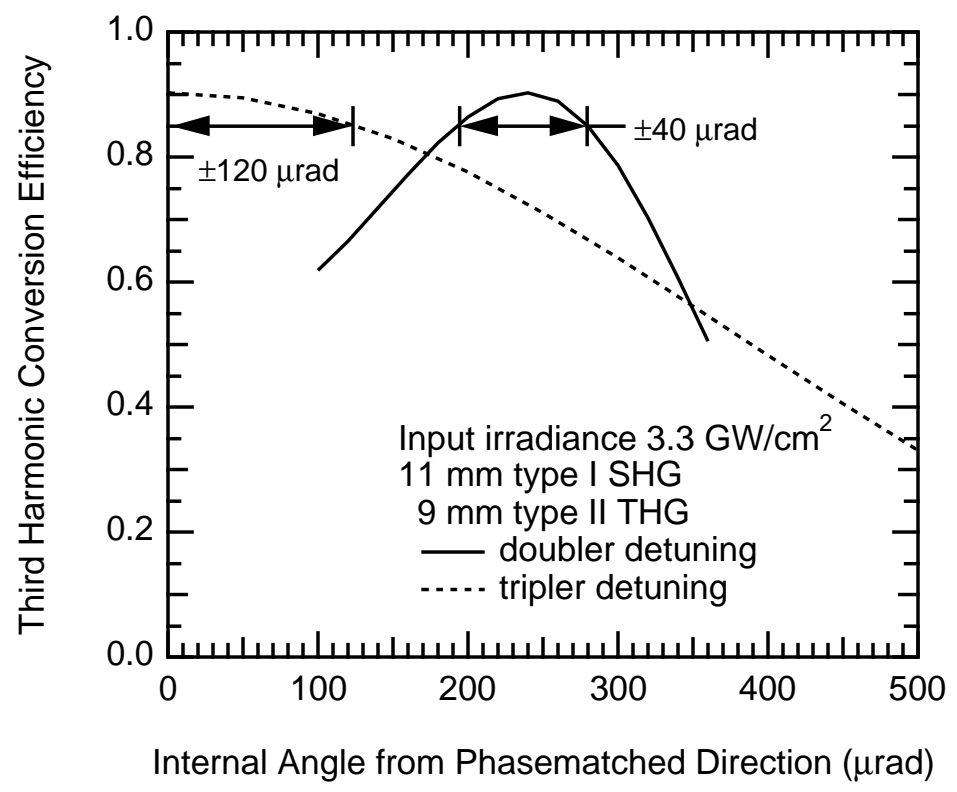

Figure 2. Third harmonic conversion versus internal detuning angle from phasematched direction for an $11 \mathrm{~mm}$ type I doubler and a $9 \mathrm{~mm}$ type II tripler at an input drive irradiance of $3.3 \mathrm{GW} / \mathrm{cm}^{2}$. A detuning of $\pm 40 \mu \mathrm{rad}$ internal to the doubler reduces third harmonic generation efficiency from $90.8 \%$ to $85 \%$. The tripler is three times less sensitive to internal detuning.

Table 4. Angular sensitivity terms

\begin{tabular}{|l|c|l|}
\hline Effect & $\begin{array}{l}\text { Internal angle } \\
\text { allocation }(\mu \mathrm{rad})\end{array}$ & Comments \\
\hline \hline alignment & \pm 26 & $\begin{array}{l}\text { root-sum-square accumulation of COMS, reference surface, and beam } \\
\text { alignments }\end{array}$ \\
\hline temperature & \pm 5 & $\begin{array}{l}\text { doubler thermally tunes at } 50 \mu \mathrm{rad} /{ }^{\circ} \mathrm{C} \text {; tripler at } 200 \mu \mathrm{rad} /{ }^{\circ} \mathrm{C} \\
\rightarrow \Delta \mathrm{T} \leq \pm 0.1^{\circ} \mathrm{C}\end{array}$ \\
\hline beam divergence & \pm 13 & $\begin{array}{l}\text { divergence with phase plate } \leq 35 \mu \mathrm{rad} \text { (external); } 20 \mu \mathrm{rad} \text { (external) allocated to } \\
\text { beam }\end{array}$ \\
\hline $\begin{array}{l}\text { phasematching } \\
\text { uniformity }\end{array}$ & $\begin{array}{l}\text { CCI and COMS data indicate that } 10 \mu \mathrm{rad} \text { is achievable with high quality } \\
\text { crystals }\end{array}$ \\
\hline $\begin{array}{l}\text { surface figure (long } \\
\text { scale) }\end{array}$ & \pm 30 & $\begin{array}{l}45 \mu \text { rad (external) is allocated among mounting effects, surface figure of } \\
\text { crystal, and gravitational sag }\end{array}$ \\
\hline $\begin{array}{l}\text { Total (root-sum- } \\
\text { square) }\end{array}$ & \pm 40 & allocation based on sensitivity of tripling efficiency to doubler detuning \\
\hline
\end{tabular}

\section{Crystal Deformation and Mounting}

Deformation of the conversion crystal surfaces leads to wavefront deformation as the laser beam enters the crystal. These wavefront aberrations cause local variations in phasematching conditions that reduce conversion efficiency. Such deformations of the crystal surfaces can be caused by crystal cutting operations, the crystal mount, and gravitational sag.

When supported only at its corners, as is currently the case for Nova and Beamlet conversion crystals, the deflection of a 41 $\mathrm{cm}$ square crystal under its own weight can result in a conversion efficiency reduction of 2.5\%. Shown in Figures 3 and 4, respectively, are contour plots of displacement calculated for a $41 \mathrm{~cm}$ square by $1.1 \mathrm{~cm}$ thick type I KDP doubler and a $41 \mathrm{~cm}$ 


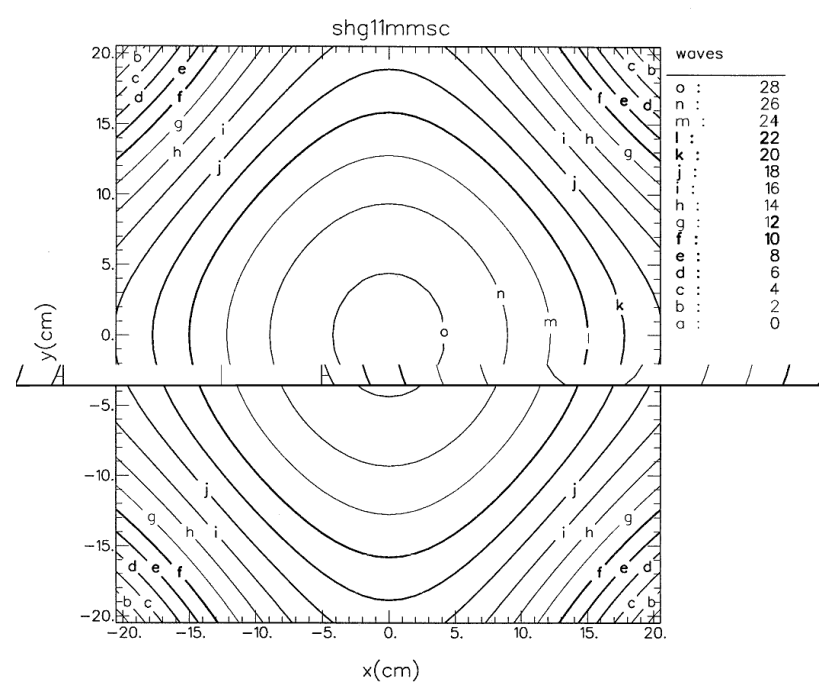

Figure 3. Contour plot of the calculated gravitational deflection of a $41 \mathrm{~cm}$ square by $1.1 \mathrm{~cm}$ type I KDP doubler simply supported at four corners. Gravity acts parallel to the plate normal direction.

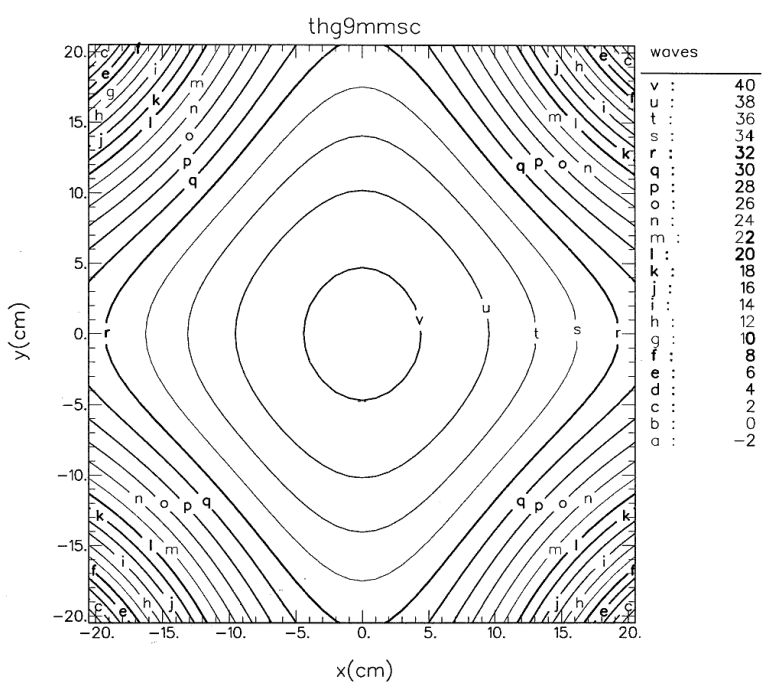

Figure 4. Contour plot of the calculated gravitational deflection of a $41 \mathrm{~cm}$ square by $0.9 \mathrm{~cm}$ type II KDP tripler simply supported at four corners. Gravity acts parallel to the plate normal direction.

square by $0.9 \mathrm{~cm}$ thick KDP tripler. The displacements are given in waves at $1 \mu \mathrm{m}$, and are calculated for boundary conditions of simple support in the four corners with gravity acting parallel to the plate normal direction. Under these conditions, the maximum deflection of the doubler is $28 \mu \mathrm{m}$ and the maximum deflection of the tripler is $40 \mu \mathrm{m}$.

The gravitational deflection of the crystals can be reduced significantly by supporting them completely around their perimeter. With simple support on all four edges, the doubler sag is calculated to be $4 \mu \mathrm{m}$ and tripler sag is reduced to less than $7 \mu \mathrm{m}$, resulting in a conversion efficiency reduction of only $0.1 \%$. If clamped boundary conditions are applied along all four edges, doubler sag is calculated to be less than $1.5 \mu \mathrm{m}$ and tripler sag is found to be less than $2 \mu \mathrm{m}$. In this case there is no discernible loss in conversion efficiency. The crystal deflections and the corresponding conversion efficiency reductions for these various sets of boundary conditions are summarized in Table 5. We anticipate that the boundary conditions for real mounts will lie somewhere between the idealized cases of simple support and clamped support.

The design of the Final Optics Cell (FOC) for the National Ignition Facility laser provides full edge support for both the

Table 5. Calculated crystal deflections for various boundary conditions

\begin{tabular}{|l|c|c|c|}
\hline Boundary condition & $\begin{array}{c}\text { Doubler sag- 11mm type I } \\
\text { (waves @ } 1 \mu \mathrm{m}) \dagger\end{array}$ & $\begin{array}{c}\text { Tripler sag- 9mm type II } \\
(\text { waves @ } 1 \mu \mathrm{m}) \dagger\end{array}$ & Efficiency loss \\
\hline \hline simple support all four corners & 28 & 40 & $2.5 \%$ \\
\hline simple support all four edges & 4 & $<7$ & $0.1 \%$ \\
\hline clamped support all four edges & $<1.5$ & $<2$ & $0 \%$ \\
\hline
\end{tabular}

$\dagger$ gravity acts parallel to the plate normal direction

doubler and tripler crystals, as illustrated in Figure 5. This monolithic cell also contains the final focus lens, and an optional diffractive optic plate. A two-thirds scale, multi-piece prototype FOC has been fabricated by single-point diamond turning. The profile of the crystal mounting surface has been measured by phase-shift interferometry, as shown in Figure 6 . This surface has been found to be flat to approximately $1 \mu \mathrm{m}$, with a maximum slope of about $8 \mu \mathrm{rad}$. 


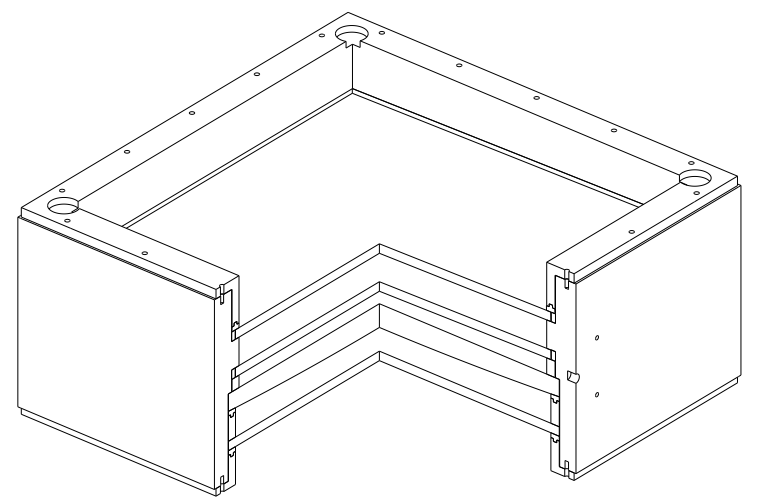

Figure 5. Illustration of the National Ignition Facility Final Optics Cell (FOC). In this figure, the beam enters from the top, passing through the doubling crystal, the tripling crystal, the final focus lens, and an optional diffractive optic plate. The crystals will be held against the precision mounting surfaces by compliant pads.

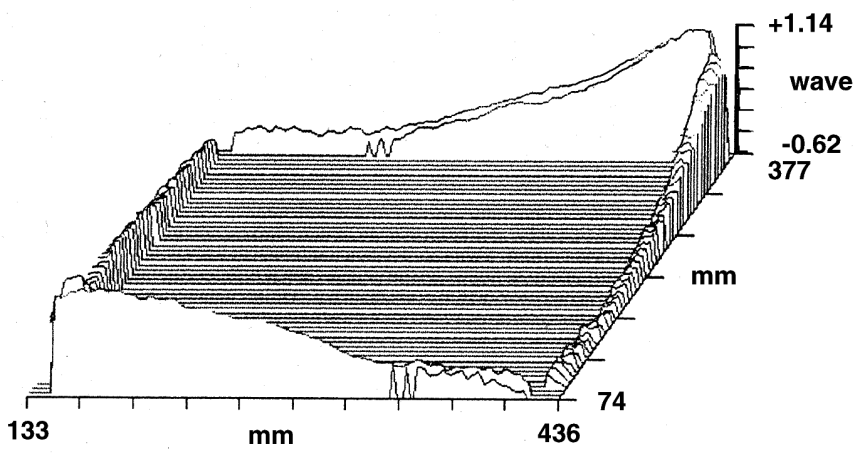

Figure 6. Measured surface profile of the 2/3-scale prototype Final Optics Cell. This measurement was performed with a phase-shift interferometer operating at $632.8 \mathrm{~nm}$. The surface is flat to approximately $1 \mu \mathrm{m}$.

\section{Crystal Quality}

Highly efficient frequency conversion requires very good crystal quality. Third harmonic generation experiments on Beamlet using the $37 \mathrm{~cm}$ frequency conversion crystals produced lower whole beam energy conversion efficiency values than were obtained in experiments using the $32 \mathrm{~cm}$ crystals. ${ }^{2}$ Although whole beam energy conversion efficiency was only $72 \%$, an examination of near field images taken during recent Beamlet experiments indicates that some regions of the aperture were converting in excess of $80 \%$ while other regions showed much lower efficiency. ${ }^{4}$ The phase maps of the $37 \mathrm{~cm}$ doubling and tripling crystals, which are presented in Figures 7 and 8, show significant structure. Furthermore, phasematching angle measurements made during crystal cutting and finishing indicate an internal phasematching angle variation of at least $63 \mu \mathrm{rad}$ in the $37 \mathrm{~cm}$ doubler, whereas the $32 \mathrm{~cm}$ doubler showed a variation of only $5 \mu \mathrm{rad}$. On the other hand, the $32 \mathrm{~cm}$ and $37 \mathrm{~cm}$

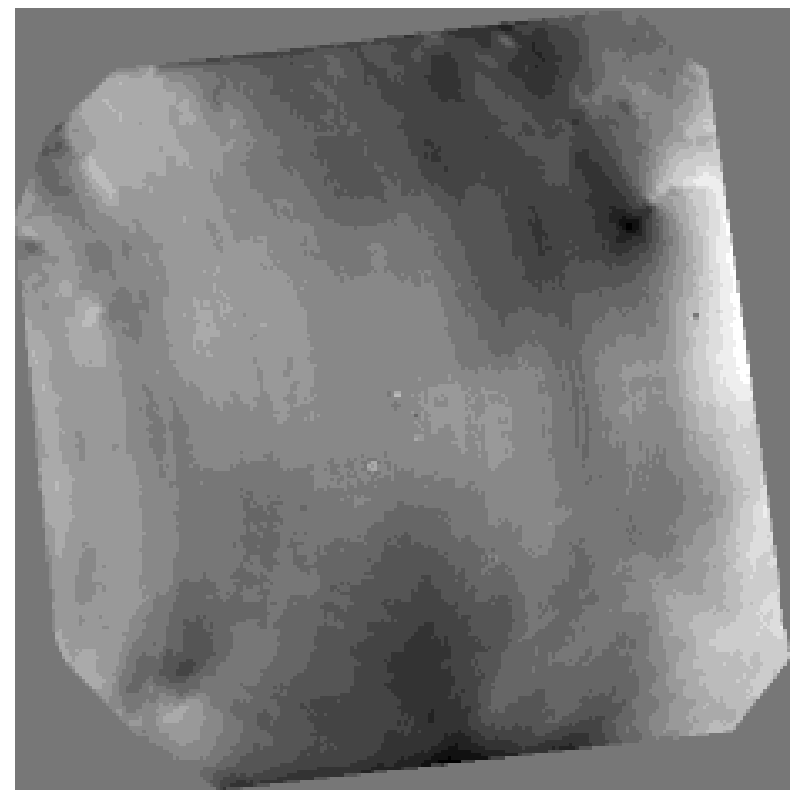

Figure 7. Phase map of the $37 \mathrm{~cm}$ doubler, obtained by phase-shift interferometry.

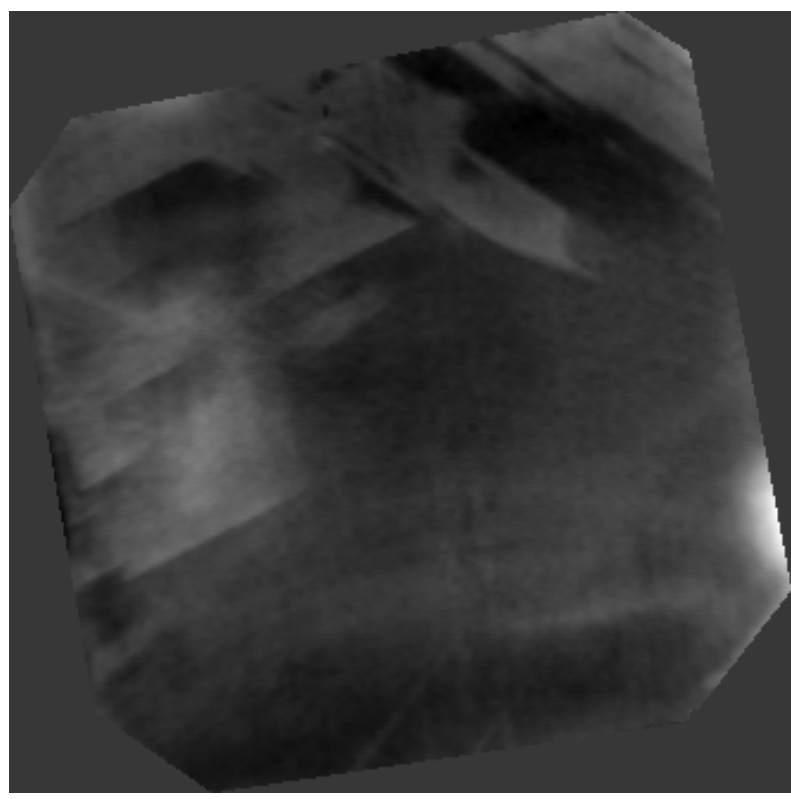

Figure 8 . Phase map of the $37 \mathrm{~cm}$ tripler, obtained by phase-shift interferometry. 
tripler crystals displayed similar levels of phasematching angle variation: $19 \mu \mathrm{rad}$ and $16 \mu \mathrm{rad}$, respectively. Consequently we believe that the differences in conversion efficiencies that we have measured with the $32 \mathrm{~cm}$ and $37 \mathrm{~cm}$ crystals is due to the poorer quality of the $37 \mathrm{~cm}$ crystals, and we are pursuing further off-line studies to better characterize these crystals.

\section{Summary}

We have developed a preliminary error budget for the third harmonic generator for the NIF laser driver. This budget is based on a root-sum-square accumulation of error from all of the various effects that can reduce conversion efficiency. Because some, but not all, of these effects can be treated as statistically independent, this error budget sets an upper bound on the allowable magnitude of these error sources. Lower bounds can be established by direct addition of the effects of all of these error terms. It is obvious that the allowable magnitudes of these error terms will have to be significantly reduced to meet this tighter budget. Consequently, a much more careful apportionment of the error budget will be required. The most realistic budget will lie between these two sets of bounds, but extensive modeling will be needed to establish the interactions of the various error terms. Such a budget will be developed early in the Title II engineering phase of NIF.

We have modeled the gravitational sag of the frequency conversion crystals under worst-case conditions, i.e. gravity acting normal to the conversion crystal plates, and found that full edge support of the crystals will nearly eliminate efficiency reductions due to that effect. Measurements of our first prototype Final Optics Cell show that it achieved a very flat mounting surface.

An analysis of Beamlet results and limited crystal characterization data indicate that crystal quality is the primary cause of the reduced conversion efficiency that has been observed with the $37 \mathrm{~cm}$ conversion crystals during Beamlet experiments.

\section{Acknowledgments}

We acknowledge the LLNL engineers, technicians, scientists, and support personnel who make Beamlet's daily operation possible. This work was performed under the auspices of the U.S. Department of Energy by Lawrence Livermore National Laboratory under Contract No. W-7405-Eng-48.

\section{References}

1. B. M. Van Wonterghem, J. R. Murray, J. H. Campbell, D. R. Speck, C. E. Barker, I. C. Smith, D. F. Browning, and W. C. Behrendt, "System Description and Initial Performance Results for Beamlet," ICF Quarterly Report, Vol. 5, No. 1, pp 1-17, Lawrence Livermore National Laboratory, Livermore, CA, UCRL-LR-105821-95-1, Oct. - Dec. 1994.

2. C. E. Barker, B. M. Van Wonterghem, J. M. Auerbach, R. J. Foley, J. R. Murray, J. H. Campbell, J. A. Caird, D. R. Speck, and B. Woods, "Design and performance of the Beamlet laser third harmonic frequency converter," in First Annual International Conference on Solid-State Lasers for Application to Inertial Confinement Fusion, Michel Andre, Howard T. Powell, Editors, Proc. SPIE 2633, pp. 398-404 (1995).

3. R. S. Craxton, "High Efficiency Tripling Schemes for High-Power Nd:Glass Lasers," IEEE J. Quantum Electron., QE17, No. 9, pp. 1771-1782, Sept. 1981.

4. P. J. Wegner, B. M. Van Wonterghem, C. E. Barker, J. A. Caird, S. N. Dixit, M. A. Henesian, J. T. Hunt, L. G. Seppala, and C. E. Thompson, "Third-Harmonic Performance of the Beamlet Prototype Laser," presented at the Second Annual International Conference on Solid-State Lasers for Application to Inertial Confinement Fusion, (paper 10-1), Paris, France, October 22 - 25, 1996. 


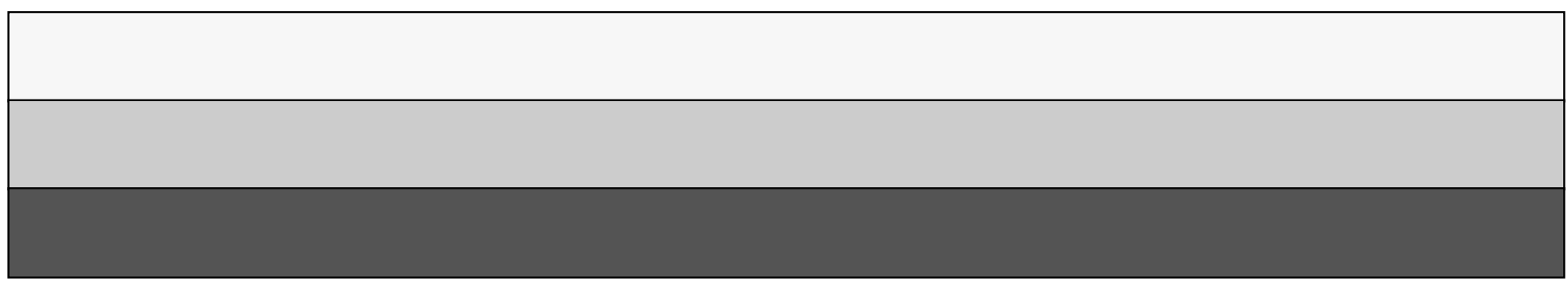

